\title{
Network pharmacology of triptolide in cancer cells: implications for transcription factor binding
}

\author{
Ean-Jeong Seo ${ }^{1} \cdot$ Mona Dawood $^{1,2} \cdot$ Annika K. Hult $^{3} \cdot$ Martin L. Olsson $^{3} \cdot$ Thomas Efferth $^{1}$ (i)
}

Received: 20 April 2021 / Accepted: 10 June 2021 / Published online: 2 July 2021

(c) The Author(s) 2021

\begin{abstract}
Summary
Background Triptolide is an active natural product, which inhibits cell proliferation, induces cell apoptosis, suppresses tumor metastasis and improves the effect of other therapeutic treatments in several cancer cell lines by affecting multiple molecules and signaling pathways, such as caspases, heat-shock proteins, DNA damage and NF-кB. Purpose We investigated the effect of triptolide towards NF-кB and GATA1. Methods We used cell viability assay, compare and cluster analyses of microarraybased mRNA transcriptome-wide expression data, gene promoter binding motif analysis, molecular docking, Ingenuity pathway analysis, NF-KB reporter cell assay, and electrophoretic mobility shift assay (EMSA) of GATA1. Results Triptolide inhibited the growth of drug-sensitive (CCRF-CEM, U87.MG) and drug-resistant cell lines (CEM/ADR5000, U87. MG $\Delta$ EGFR). Hierarchical cluster analysis showed six major clusters in dendrogram. The sensitive and resistant cell lines were statistically significant $\left(p=0.65 \times 10^{-2}\right)$ distributed. The binding motifs of NF- $\mathrm{\kappa B}(\mathrm{Rel})$ and of GATA1 proteins were significantly enriched in regions of $25 \mathrm{~kb}$ upstream promoter of all genes. IPA showed the networks, biological functions, and canonical pathways influencing the activity of triptolide towards tumor cells. Interestingly, upstream analysis for the 40 genes identified by compare analysis revealed ZFPM1 (friend of GATA protein 1) as top transcription regulator. However, we did not observe any effect of triptolide to the binding of GATA1 in vitro. We confirmed that triptolide inhibited NF- $\mathrm{KB}$

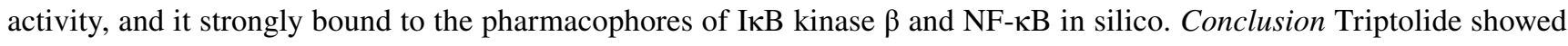

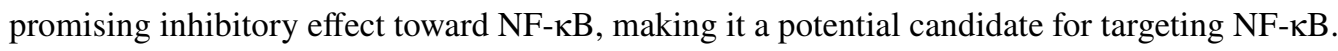

Keywords Microarrays $\cdot$ Natural products $\cdot$ Network pharmacology $\cdot$ Phytochemicals $\cdot$ Precision medicine

\section{Introduction}

Triptolide, a diterpenoid triepoxide, is predominantly an active natural product isolated from the medicinal plant Tripterygium wilfordii Hook F (TWHF) [1]. Triptolide exhibits

Ean-Jeong Seo and Mona Dawood contributed equally.

Thomas Efferth

efferth@uni-mainz.de

1 Department of Pharmaceutical Biology, Institute of Pharmaceutical and Biomedical Sciences, Johannes Gutenberg University, Staudinger Weg 5, 55128 Mainz, Germany

2 Department of Molecular Biology, Faculty of Medical Laboratory Sciences, Al-Neelain University, Khartoum, Sudan

3 Division of Hematology and Transfusion Medicine, Department of Laboratory Medicine, Lund University, 22184 Lund, Sweden potent pharmacological activities against inflammation, fibrosis, cancer, viral infection, oxidative stress and osteoporosis [2-4]. Triptolide has a similar structure as steroid hormones, and it showed high binding affinity to a nuclear receptor, human estrogen receptor alpha (ER $\alpha)$ [5]. It selectively inhibits the activity of peroxiredoxin I, which has crucial functions in the development of cancer and inflammation [6]. The XBP1 subunit of the transcription factor TFIH core complex is one of the molecular targets of triptolide, which is important for the inhibitory activity of triptolide to RNA polymerase II-mediated transcription [7]. This feature provides one explanation of the activity of triptolide against several diseases such as inflammation and cancer [8-10].

Triptolide shows proapoptotic and anti-proliferative effects on tumor cell lines in vitro and reduces the tumor size or inhibits tumor growth in vivo. It inhibits cell proliferation, induces cell apoptosis, suppresses tumor metastasis and improves the effect of other therapeutic treatments in several cancer cell lines [11]. It affects multiple molecules 
and signaling pathways, such as caspases, heat-shock proteins, DNA damage and NF-KB. It also enhances chemoradiosensitivity in cancer therapy [12].

Nowadays, targeting transcription factor drivers in cancer is becoming a successful strategy for treatment of cancer [1]. This mainly based on the fact that most of the oncogenes involved in tumorigenesis processes are transcription factors such as forkhead box O (FOXO), nuclear factor kappa B (NF-kb), Krüppel-like factor 8 (KLF8), MYC, GATA binding factor (GATA1), activator protein 1 (AP-1), etc. [13, 14].

$\mathrm{NF}-\mathrm{kB}$ is a family of transcription factors that are constitutively active in different types of tumors. NF- $\mathrm{KB}$ has been identified as a key player in carcinogenesis process, since it has a role in activation of cellular pathways such as: cell proliferation, survival, apoptosis, angiogenesis, and metastasis [15]. Hence, targeting NF- $\kappa B$ is of significant therapeutic value. NF- $\mathrm{kB}$ is located in the cytoplasm in inactive form by its binding to inhibitory proteins (I $\mathrm{B}$ ). In the presence of specific stimuli, I $\kappa \mathrm{B}$ is phosphorylated by the I $\kappa \mathrm{B}$ kinase (IKK) and eventually degraded. Activated NF- $\kappa B$ is now free to translocate to the nucleus and binds to its specific DNA sequences at the cis-acting elements of the target genes enhancing their expression [16].

The GATA-binding factor (GATA) proteins constitute a large family of transcription factors. In mammals, it is composed of six members (GATA1-GATA6) that can be further classified into two subfamilies based on their expression profile and the structure of the gene [17]. GATA1 and its friend Zinc Finger Protein (ZFPM1, FOG1) are transcription factors and transcription regulators, respectively [18]. They regulate the differentiation of the erythroid and megakaryocytic cell lineages by regulating the expression of the key genes related to cell proliferation, cell differentiation, and apoptosis [19]. ZFPM1 binds to GATA1 to form a heterodimer complex to synergistically activate transcription at the specific regulatory region of the genes. Then, the expressed genes enable differentiation of hematopoietic cells to both erythroid and megakaryocytic cells [20]. Moreover, several studies reported that the deregulation of ZFPM1 and its pathway contributes to the initiation of hematologic malignancies. Therefore, GATA1 is considered a potential target for cancer therapy [21].

In this study, we investigated the cytotoxic activity of triptolide in tumor cell lines. Moreover, we carried out COMPARE and hierarchical cluster analyses for 60 cell lines of the National Cancer Institute (NCI, United States) that represent 9 different types of tumors. Then, we were interested to perform pathway and motif analyses using the 40 genes identified by the microarray. Later, we examined the inhibitory effect of triptolide towards NF- $\mathrm{KB}$ using in silico molecular docking and NF-KB reporter cell assay, since our bioinformatics analysis showed that triptolide affects $\mathrm{NF}-\mathrm{KB}$. Besides, we also studied the effect of triptolide to
GATA proteins, because GATA proteins were predicted to bind triptolide by our motif binding analyses in this study.

\section{Materials and methods}

\section{Cell lines}

Drug-sensitive CCRF-CEM and multidrug-resistant Pglycoprotein-overexpressing CEM/ADR5000 leukemic cells were kindly given by Prof. Axel Sauerbrey (Department of Pediatrics, University of Jena, Germany). Cells were cultured in RPMI1640 medium supplemented with $10 \%$ fetal bovine serum (FBS) and $1 \%$ penicillin $(1,000 \mathrm{U} / \mathrm{mL}) / \mathrm{strep}-$ tomycin $(100 \mu \mathrm{g} / \mathrm{mL})(\mathrm{P} / \mathrm{S})$ (Life Technologies, Darmstadt, Germany). Doxorubicin $(5,000 \mathrm{ng} / \mathrm{mL})$ was supplied to retain overexpression of $\mathrm{P}-\mathrm{gp}(M D R 1, A B C B 1)$ in resistant CEM/ADR5000 leukemic cells [26]. Human brain glioblastoma cell line U87.MG and the U87.MG $\Delta$ EGFR that is transfected with a plasmid carrying an EGFR gene with a deletion of exons 2-7 were obtained from Dr. W. K. Cavenee (Ludwig Institute for Cancer Research, San Diego, CA, United States). The cell lines were cultured with $800 \mathrm{ng} / \mathrm{mL}$ geneticin [22, 23].

The panel of 60 human tumor cell lines of the Development of Therapeutics Program of the National Cancer Institute (NCI, USA) included leukemia, melanoma, non-small cell lung cancer, colon cancer, renal cancer, ovarian cancer, breast cancer, prostate carcinoma cells, and tumor cells of the central nervous system [24].

\section{Cell viability assay}

The cytotoxic activities of triptolide (Sigma Aldrich, Taufkirchen, Germany; Fig. 1A) were evaluated by the resazurin assay [25]. This assay is based on reduction of the indicator dye, resazurin, to the highly fluorescent resorufin by viable cells. Aliquots of 5,000 cells/ $100 \mu \mathrm{L}$ of U87.MG and U87.MG $\triangle$ EGFR were placed in 96-well plates and incubated for one day before treatment. However, for leukemic cells, 10,000 cells $/ 100 \mu \mathrm{L}$ cells were seeded into 96-well plates and immediately treated. Twenty microliters of resazurin $0.01 \% \mathrm{w} / \mathrm{v}$ solution were added to each well after $72 \mathrm{~h}$ at $37^{\circ} \mathrm{C}$ incubation, and the plates were incubated at $37^{\circ} \mathrm{C}$ for $4 \mathrm{~h}$. Fluorescence was detected by an Infinite M2000 Proplate reader (Tecan, Crailsheim, Germany) with an excitation wavelength of $544 \mathrm{~nm}$ and an emission wavelength of $590 \mathrm{~nm}$. Each experiment was carried out at least three times with six replicates each. The viability was analyzed based on a comparison with untreated cells. Fifty percent inhibition $\left(\mathrm{IC}_{50}\right)$ values imply the drug concentrations needed to inhibit $50 \%$ of cell proliferation and were calculated from a 
A<smiles>CC(O)C12CCC3=C(COC3=O)[C@@H]1CC1OC13C21OC1[C@@H]1O[C@]13C(C)C</smiles>

B

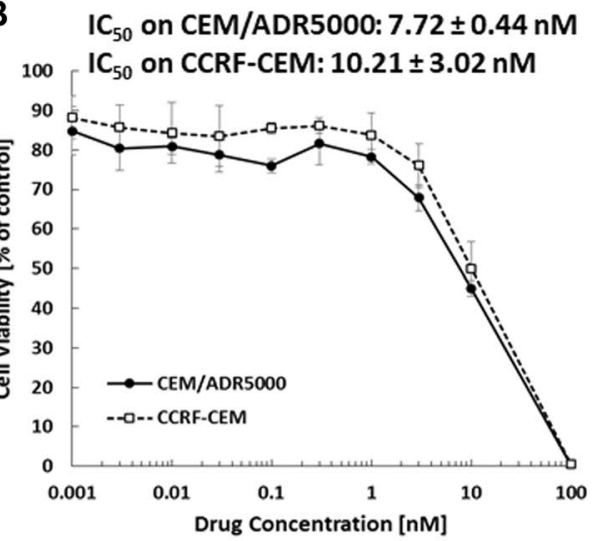

C IC $C_{50}$ on U87MG: $0.025 \pm 0.002 \mu \mathrm{M}$

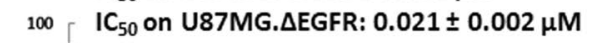

${ }_{90}$ 只.

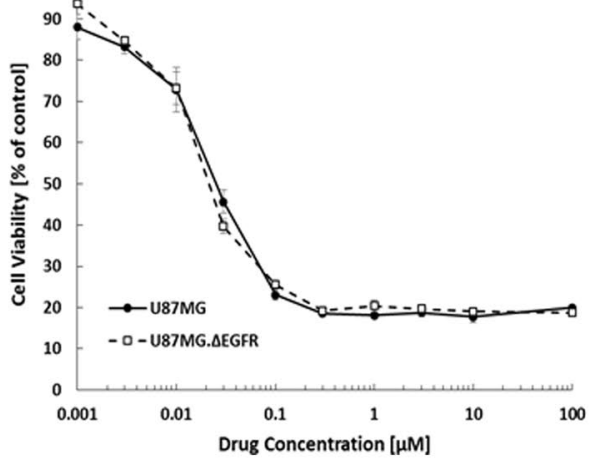

Fig. 1 Cytotoxicity of triptolide against cancer cells. Chemical structure of triptolide A. Cytotoxic effect of triptolide against CEM/ADR5000 and CCRF-CEM B, and U87.MG and U87.MG $\Delta$ EGFR $\mathbf{C}$

calibration curve by linear regression using Microsoft Excel $[26,27]$.

\section{Compare and cluster analyses of microarray-based mRNA transcriptome-wide expression data}

The mRNA microarray hybridization of the NCI cell lines has been published at the NCI Web site (http://dtp.nci.nih. gov) $[28,29]$. COMPARE analyses were used to obtain rankordered lists of genes expressed in the NCI cell lines. The detailed method as a tool to determine candidate genes for drug resistance and sensitivity has been previously published [30-33]. In order to identify COMPARE rankings, a scale index of correlation coefficients (R-values) was generated from $\operatorname{Iog}_{10} \mathrm{IC}_{50}$ values of test compounds and microarraybased mRNA expression values. Greater mRNA expression correlated with enhanced drug resistance in the standard COMPARE, whereas greater mRNA expression in cell lines indicated drug sensitivity in reverse COMPARE analyses. Pearson's correlation test was used to calculate significance values and rank correlation coefficients as relative measure for the linear dependency of two variables.

For hierarchical cluster analyses, objects were classified by calculation of distances according to the closeness of between individual distances. All objects were displayed into cluster trees (dendrograms). Merging of objects with similar features leads to cluster formation, where the length of the branch implies the degree of relation. Distances of subordinate cluster branches to superior cluster branches serve as criteria for the closeness of clusters. Therefore, objects with tightly related features were clustered closely together, if separation of objects in the dendrogram increased with progressive dissimilarity. Hierarchical clustering and heat map analyses were carried out using clustered image map (CIM) miner software by the one matrix CIM (https://discover.nci. nih.gov/cimminer/oneMatrix.d) [34].

\section{Transcription factor gene promoter binding motif analysis}

The top 40 genes, which directly or inversely correlated with $\log _{10} \mathrm{IC}_{50}$ values of the NCI cell lines in COMPARE analysis, were submitted to binding motif analysis. Promoter sequences $25 \mathrm{~kb}$ upstream of exon 1 of the corresponding genes were retrieved from UCSC Genome Browser Gene Sorter (http://genome.ucsc.edu). Promoter sequences were checked using the SeqPos tool implemented in the Galaxy Cistrome software [35].

\section{Molecular docking}

The interaction energy of triptolide with NF-кB pathway proteins was predicted using molecular docking: І-кB kinase $\beta$, I-кB kinase $\beta$-NEMO (NF-кB essential modulator) complex, NF-кB, and NF-кB-DNA complex. The protocol for molecular docking was reported by us [36]. Protein structures using X-ray crystallography were obtained from PDB database (http://www.rcsb.org/). I-кB kinase $\beta$ (PDB ID:3RZF), I-KB kinase $\beta$-NEMO complex (PDB ID:3BRT), NF-кB (p52/RelB heterodimer, PDB ID:3DO7), and NFкB-DNA complex (p50/p65 heterodimer bound to DNA, PDB ID: IVKX) were used in our study.

A grid box was defined for docking spaces in each protein according to its pharmacophores. Docking parameters were set to 250 runs and 2,500,000 energy evaluations for each docking. Dockings were performed three times independently. Lamarckian Genetic Algorithm was chosen for docking calculations. For the visualization of docking results, AutodockTools-1.5.7rcl was used. The surface representation image showing the binding pocket of proteins was made with Visual Molecular Dynamics (VMD) software developed with NIH support by the Theoretical and Computational Biophysics group at the Beckman Institute, 
University of Illinois at Urbana-Champaign (http://www.ks. uiuc.edu/Research/vmd/).

\section{Ingenuity pathway analysis}

Deregulated genes identified by COMPARE analysis as factors determining cellular responsiveness to triptolide were subjected to pathway analysis, in order to determine the biological function of these genes. Forty genes were imported into the Ingenuity Pathway Analysis (IPA) software (Qiagen Bioinformatics, Redwood City, CA, U.S.A) in Excel format [37].

Core analyses were carried out with general settings: "human" as species and "cell line" as type of biological sample. Canonical pathways, diseases and functions, and upstream regulators were determined by Fisher's exact test at a significance value of $p<0.05$. IPA core analyses identifies key regulators and networks in human cell lines [37, 38].

\section{NF-KB reporter cell assay}

HEK293 cells stably expressing HEK-Blue-Null1 vector and SEAP on a NF-KB promoter were obtained from Invivogen (San Diego, CA, USA). The cells were maintained according to manufacturer's protocol and treated with various concentrations of triptolide $(0 \mu \mathrm{M}, 1.6 \mu \mathrm{M}, 3.1 \mu \mathrm{M}, 6.3 \mu \mathrm{M}$, $12.5 \mu \mathrm{M}, 25 \mu \mathrm{M}$ and $50 \mu \mathrm{M}$ ) for $1 \mathrm{~h}$ and triptolide was not removed. Afterwards, NF- $\mathrm{KB}$ activity was induced with $100 \mathrm{ng} / \mathrm{mL}$ of TNF- $\alpha$ for $24 \mathrm{~h}$. The activation was evaluated by detecting SEAP spectrophotometrically at $630 \mathrm{~nm}$ with addition of Quanti Blue (Invivogen). The procedure has been published by us [39-41].

\section{Electrophoretic mobility shift assay (EMSA)}

Electrophoretic mobility shift assays were carried out as previously demonstrated [42]. And the sequence of the biotinylated probes (sequence from a regulatory region in $A B O$ intron 1 [GenBank KC841429]) used for testing are shown in Table 1. Gel shifts were performed using LightShift ${ }^{\mathrm{TM}}$ Chemiluminescent EMSA Kit (Thermo-Fisher, Waltham, MA, USA) and nuclear extracts were prepared from K562 cells (ATCC CCL -243 ${ }^{\mathrm{TM}}$ ) [43]. Triptolide was dissolved in DMSO to a $20 \mathrm{mM}$ stock solution which was then further diluted. Nuclear extracts were pre-incubated with three different dilutions of triptolide ( $5 \mathrm{nM}, 10 \mathrm{nM}$, and $20 \mathrm{nM})$ for $5 \mathrm{~min}$ and three concentrations $(2.5 \mathrm{nM}, 5 \mathrm{nM}$, and $100 \mathrm{nM})$ for $10 \mathrm{~min}$ to test if triptolide would inhibit GATA1 protein binding to the probes. The final dilution of DMSO was $0.1 \%$. As a vehicle control, pre-incubation was performed with $0.1 \%$ DMSO only and as a negative binding control a probe with a disrupted GATA1 site was used. Supershift assay was performed with polyclonal anti-GATA-1 $\operatorname{IgG}(1 \mu \mathrm{g} / \mu \mathrm{L}$; Active Motif, Waterloo, Belgium).

\section{Results}

\section{Cytotoxicity of triptolide towards ABC-transporter expressing tumor cell lines}

The cell viability of drug-sensitive (CCRF-CEM, U87. MG) and drug-resistant cell lines (CEM/ADR5000, U87. MG $\triangle$ EGFR) by triptolide was tested by resazurin assay. Triptolide inhibited the growth of all four cell lines after $72 \mathrm{~h}$. The $\mathrm{IC}_{50}$ values of triptolide against CCRF-CEM and CEM/ADR5000 were 10.21 and $7.72 \mathrm{nM}$, respectively (Fig. 1B). Fifty percentages of U87MG and U87MG. $\Delta$ EGFR were inhibited with 0.025 and $0.021 \mu \mathrm{M}$ triptolide, respectively (Fig. 1C).

\section{Compare and hierarchical cluster analysis of mRNA microarray data}

We studied the transcriptome-wide mRNA expression in $60 \mathrm{NCI}$ cell lines of diverse tumor types using COMPARE analysis and correlated the mRNA expression data with the $\log _{10} \mathrm{IC}_{50}$ values for triptolide, in order to identify novel molecular determinants for this compound. The scale ranking of genes, which were identified by COMPARE analysis, were applied to Pearson's rank correlation tests. Table 2 shows the top 20 genes with direct and the top 20 genes with inverse correlation coefficients.

Hierarchical cluster analysis and cluster image mapping were performed with the mRNA expression of these genes (Fig. 2). The dendrogram of the heat map can be separated into six major clusters (Fig. 2). Cluster 1 and 5 included mainly sensitive, cluster 2,3 and 4 contained mostly resistant cell lines. Cluster 6 has only resistant cell lines. The
Table 1 EMSA probe designations and sequences (wildtype and mutated GATA1binding motif highlighted in bold)

\begin{tabular}{ll}
\hline Name & Sequence 5' to 3' \\
\hline ABOil GATA F & AGAGTCTTCGCAATGCCTGGGAAAGGGAGAGATAAGGCTCACTAGCCA \\
ABOi1 GATA R & TGGCTAGTGAGCCTTATCTCTCCCTTTCCCAGGCATTGCGAAGACTCT \\
ABOi1 GAGA F & AGAGTCTTCGCAATGCCTGGGAAAGGGAGAGAGAAGGCTCACTAGCCA \\
ABOil GAGA R & TGGCTAGTGAGCCTTCTCTCTCCCTTTCCCAGGCATTGCGAAGACTCT \\
\hline
\end{tabular}




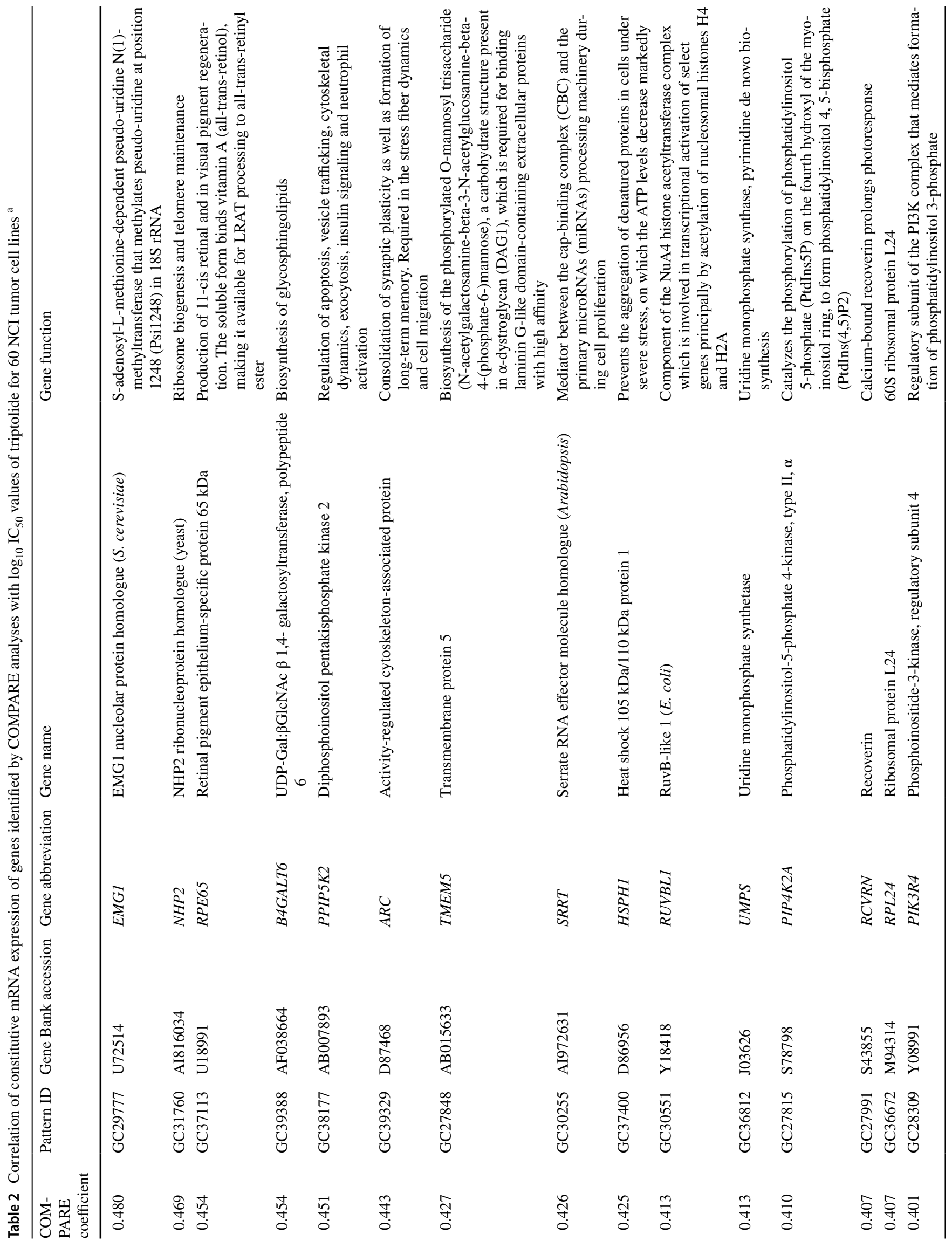




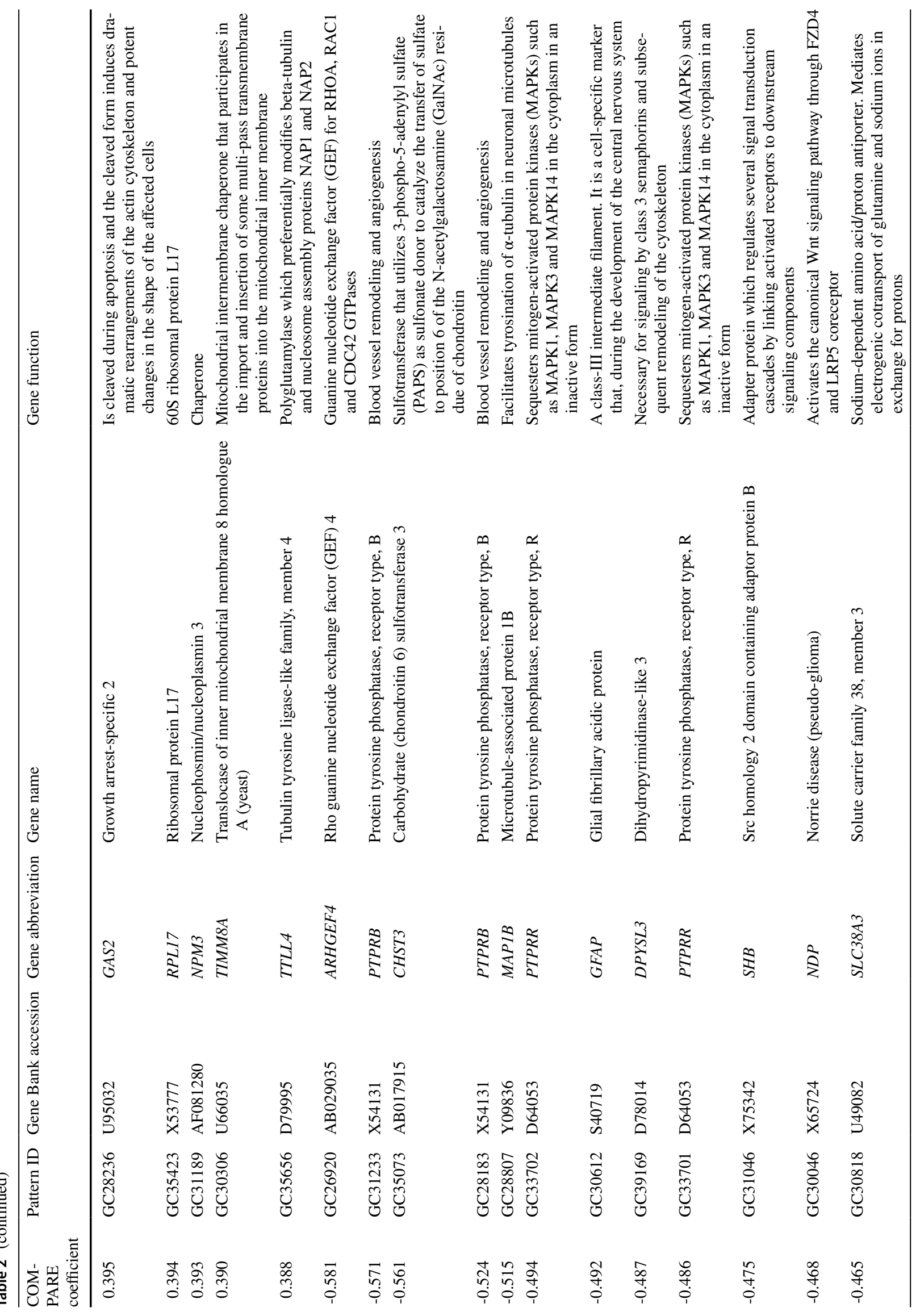




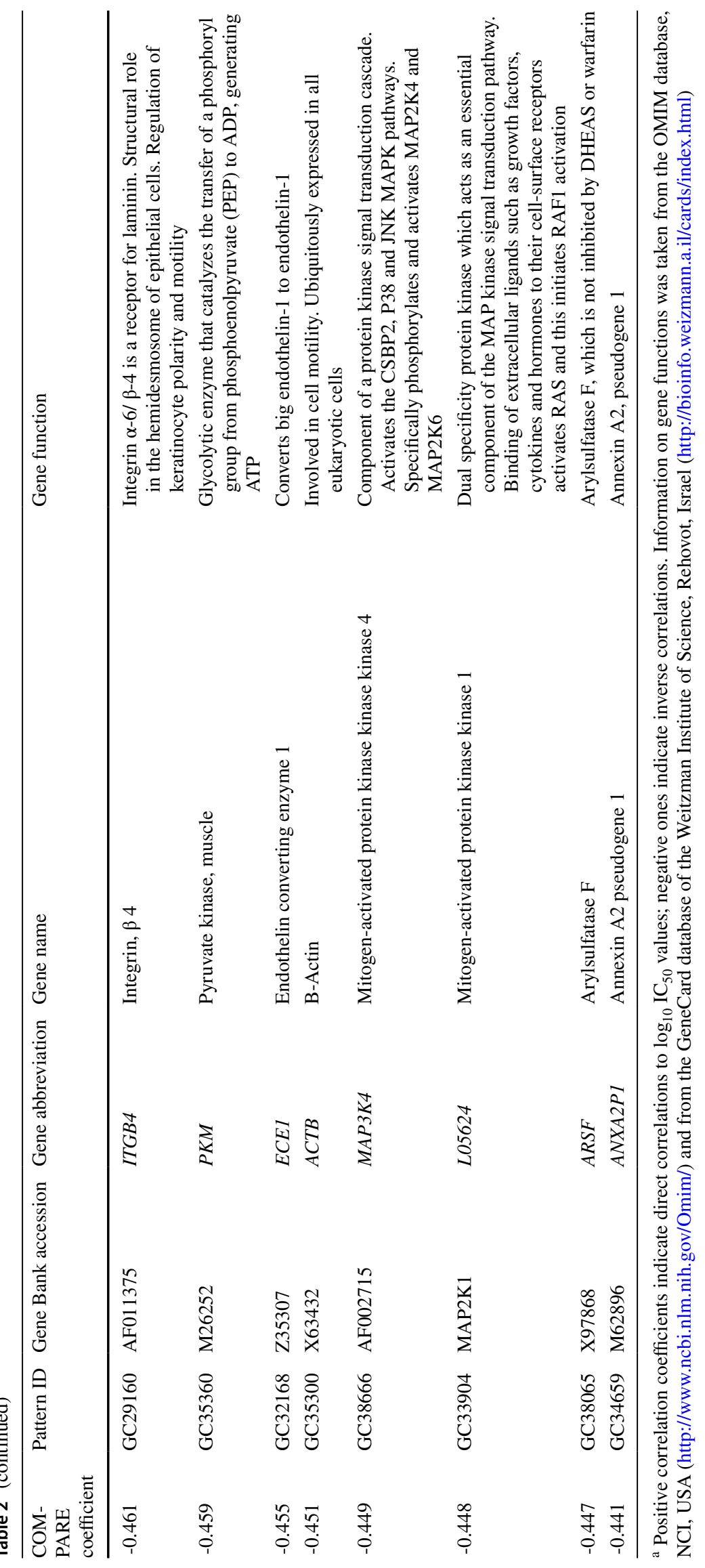


Fig. 2 Hierarchical cluster analysis and heatmap of genes expressions involved in cancer cell sensitivity to triptolide

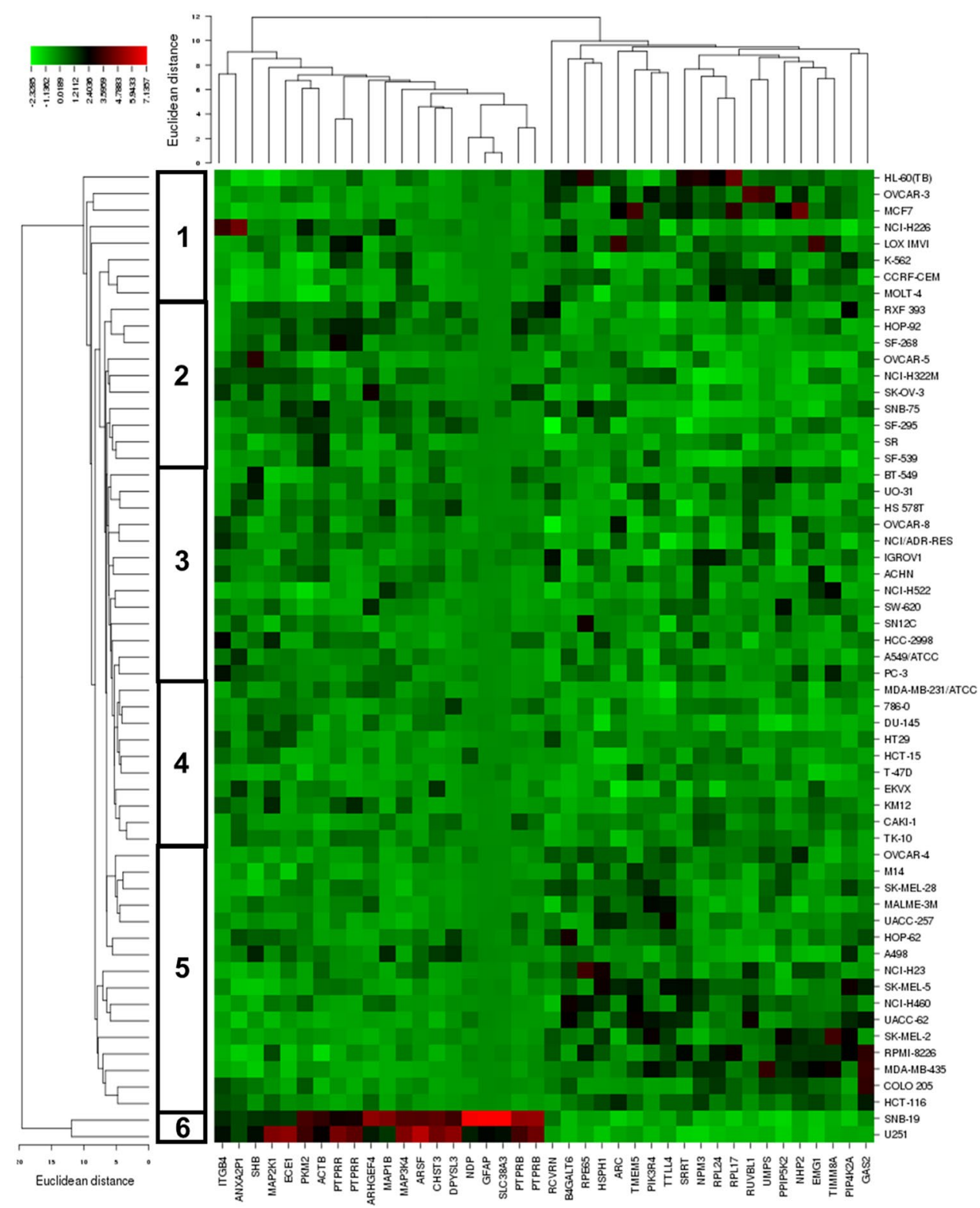

distribution of sensitive and resistant cell lines showed statistically significant $\left(p=0.65 \times 10^{-2}\right)$ (Table 3$)$.

\section{Transcription factor binding motif analysis in gene promoters}

Forty genes were identified by COMPARE analysis and the promoters of these genes contained transcription factor binding motifs for NF- $\mathrm{KB}$ and GATA proteins (GATA1, 2 and 3) (Figs. 3 and 4). The NF-кB DNA binding motif (Rel) was significantly enriched (with a $\log p$-value of -3.6) in regions of $25 \mathrm{~kb}$ upstream promoter of all genes, with 254 hits and a Z-score of -1.94 (Fig. 3). This analysis demonstrated that NF- $\kappa B$ plays a crucial role in the regulation of genes related to triptolide, as it was reported before [11, 12]. Furthermore, the binding motifs of GATA proteins 1, 2 and 3 were widely distributed in

Table 3 Separation of clusters of NCI cell lines obtained by hierarchical cluster analyses for triptolide shown in Fig. 2

\begin{tabular}{lll}
\hline & Sensitive & Resistant \\
\hline Partition & $\leq-7.948$ & $>-7.948$ \\
Cluster 1 & 6 & 2 \\
Cluster 2 & 3 & 7 \\
Cluster 3 & 5 & 8 \\
Cluster 4 & 2 & 8 \\
Cluster 5 & 13 & 3 \\
Cluster 6 & 0 & 2 \\
Chi-square test & $p=0.65 \times 10^{-2}$ & \\
\hline
\end{tabular}


Fig. 3 Binding motif analysis of $25 \mathrm{~kb}$ upstream regions of 40 genes identified by COMPARE analysis revealing the significant presence of NF- $\kappa \mathrm{B}$ binding motifs
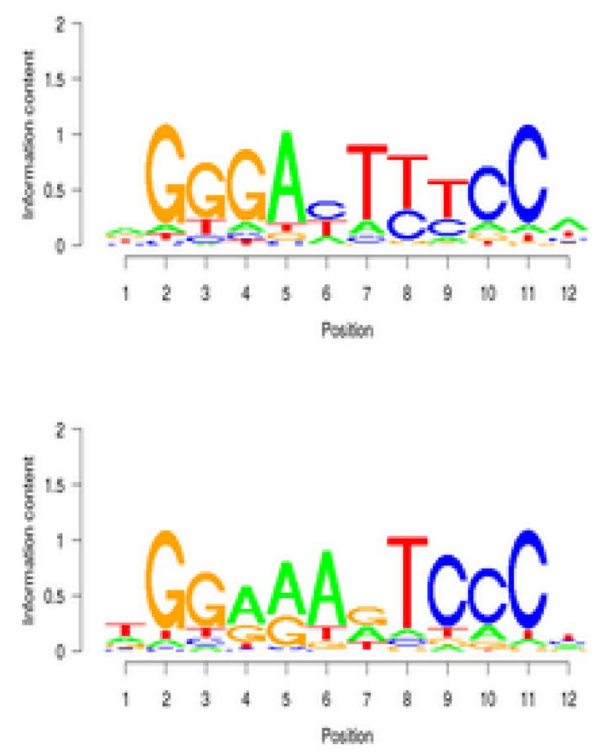

id: M00208

factors: NF-kappaB|NFKB1

DBD: RHR (Rel homology region)

hits: 254

cutoff: 1.996

zscore: -1.938

$-10 \log$ (pval): 36.371 the promoter regions of all genes, with 112 hits, a Z-score of -3.5 , with 219 hits, a Z-score of -3.7 and with 135 hits, a Z-score of -5.7, respectively (Fig. 4).

\section{Molecular docking}

In order to study the interaction of triptolide with the $\mathrm{NF}-\kappa \mathrm{B}$ pathway in more detail, molecular docking analyses were carried out using I $\mathrm{B}$ kinase $\beta$, ІкB kinase $\beta$-NEMO, NF- $\kappa B$, NF- $\kappa B$ DNA complex in silico. Triptolide strongly bound to the pharmacophores of IKB kinase $\beta$ and NF- $\kappa B$ DNA complex. Triptolide bound to IкB kinase $\beta$ with a binding energy of $-7.85 \mathrm{kcal} / \mathrm{mol}$ and to NF- $\mathrm{kB}$ DNA complex with a binding energy of $-7.68 \mathrm{kcal} / \mathrm{mol}$ (Table 4$)$.

\section{Ingenuity pathway analysis}

Deregulated genes identified by COMPARE analysis were subjected to IPA. Interestingly, pathways regulating cell death and survival, cellular development, cellular growth, cancer, post translation modification and humoral immune response, etc. appeared as top affected cellular functions and diseases (Fig. 5).

The canonical pathways analysis revealed that triptolide affects numerous pathways, such as natural killer cell signaling, ephrin receptor signaling, crosstalk between dendritic cells and natural killer cells, integrin signaling, actin cytoskeleton signaling, etc. (Fig. 6). On the other hand, the upstream regulators that were identified using IPA showed ZFPM1 as the top transcription regulators with a $p$-value of $2.85 \mathrm{E}-04$.
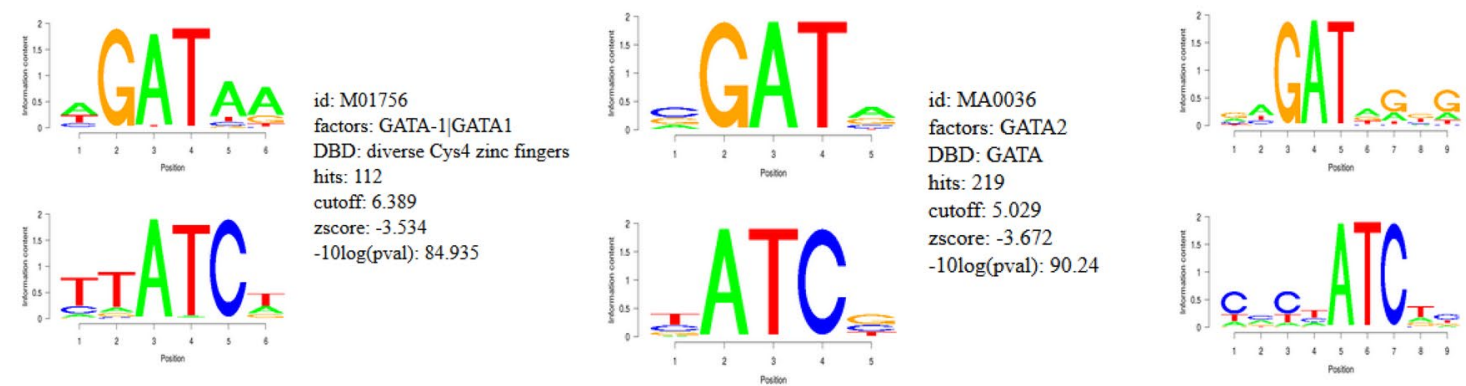

id: M00077 factors: GATA-3|GATA3 DBD: hits: 135 factors: GATA2 DBD: GATA hits: 219 cutoff: 5.029 zscore: -3.672

$-10 \log$ (pval): 90.24 cutoff: 6.258 zscore: -5.652 $-10 \log$ (pval): 186.508

Fig. 4 Binding motif analysis of $25 \mathrm{~kb}$ upstream regions of 40 genes identified by COMPARE analysis revealing the significant presence of GATA proteins binding motif 
Table 4 In silico molecular docking of triptolide on NF-KB Pathway proteins. Dockings were performed with 250 runs for each protein

\begin{tabular}{|c|c|c|c|c|c|}
\hline Protein & $\begin{array}{l}\text { Lowest energy } \\
\text { of docking (kcal/ } \\
\text { mol) }\end{array}$ & $\begin{array}{l}\text { Mean binding } \\
\text { energy (kcal/ } \\
\text { mol) }\end{array}$ & $\begin{array}{l}\text { Residues involved hydrogen } \\
\text { bond interaction with the } \\
\text { ligand }\end{array}$ & $\begin{array}{l}\text { Residues involved in hydrophobic } \\
\text { interaction with ligand }\end{array}$ & $\mathrm{pKi}(\mathrm{nM})$ \\
\hline ІкB kinase $\beta$ & $-7.85 \pm 0.26$ & $-7.78 \pm 0.32$ & LYS44, GLU100 & $\begin{array}{l}\text { LEU21, THR23, VAL29, ALA42, } \\
\text { LYS44, VAL74, MET96, } \\
\text { TYR98, CYS99, GLU100, } \\
\text { GLY102, GLU149, } \\
\text { ASN150, VAL152, ILE165, } \\
\text { ASP166, LEU167 }\end{array}$ & $1.89 \pm 0.91$ \\
\hline ІкB kinase $\beta$ - NEMO & $-6.16 \pm 0.02$ & $-6.08 \pm 0.01$ & - & $\begin{array}{l}\text { MET94, PHE97, ALA100, } \\
\text { ARG101, VAL104 }\end{array}$ & $30.72 \pm 0.12$ \\
\hline NF-кB & $-5.88 \pm 0.12$ & $-5.86 \pm 0.13$ & PHE273, PHE276, ARG290 & $\begin{array}{l}\text { GLN271, ALA272, PHE273, } \\
\text { GLY274, ASP275, PHE276, } \\
\text { ARG290, PRO292 }\end{array}$ & $49.70 \pm 10.61$ \\
\hline NF-кB DNA complex & $-7.68 \pm<0.00$ & $-7.66 \pm<0.00$ & DA18 & $\begin{array}{l}\text { DT8, DT9, DA18, DG19, DT20, } \\
\text { ARG124 }\end{array}$ & $2.35 \pm<0.00$ \\
\hline
\end{tabular}

\section{Experimental verification of binding motif analyses}

\section{NF-kB reporter assay}

Since molecular dockings and motif analysis showed the high binding affinities of triptolide to NF- $\mathrm{NB}$ and its regulator, I $\mathrm{B}$, we carried out $\mathrm{NF}-\kappa \mathrm{B}$ reporter assay using a SEAP-driven cell line. Triptolide inhibited NF- $\kappa \mathrm{B}$ activity in a dose-dependent manner (Fig. 7).

\section{EMSA of GATA following triptolide incubation}

EMSA testing was performed with probes spanning a well-characterized GATA1 site to evaluate if triptolide can inhibit binding of transcription factor GATA1. Preincubation of GATA1-containing nuclear extracts with various concentrations of triptolide did not influence the binding pattern of the GATA 1 protein to the probes. GATA1 protein binding was verified by addition of anti-GATA 1 giving rise to a clear supershift in all cases except for the negative control, for which neither a shift nor a supershift was observed when a probe with a disrupted GATA site was used (Fig. 8).

\section{Discussion}

Triptolide inhibits the proliferation and induces apoptotic cell death in several cancers. Triptolide increases the nuclear accumulation of p53 and apoptotic cell death in human prostatic epithelial cells [44].

Multi-drug resistance (MDR) is an obstacle for cancer therapy [45]. Triptolide inhibited the expression of MDR
Fig. 5 Biological functions affected by triptolide as determined by mRNA microarray hybridization and ingenuity pathway analysis

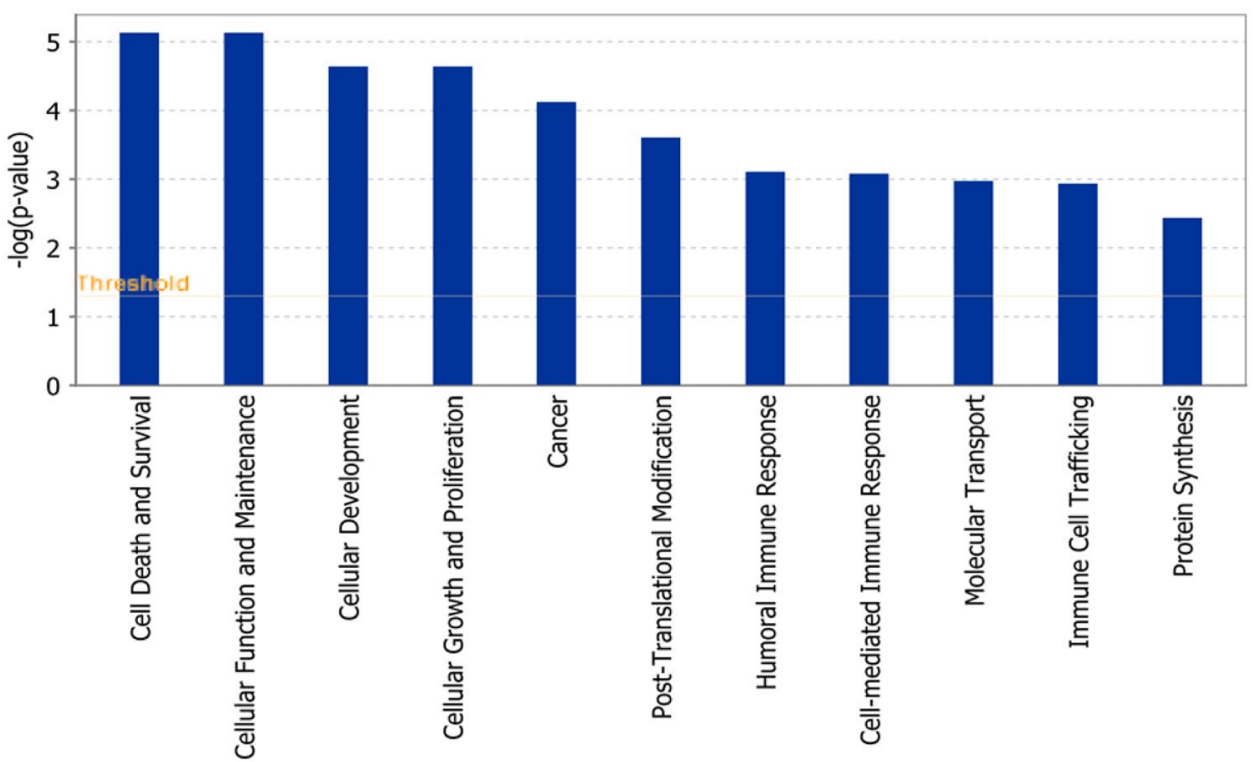




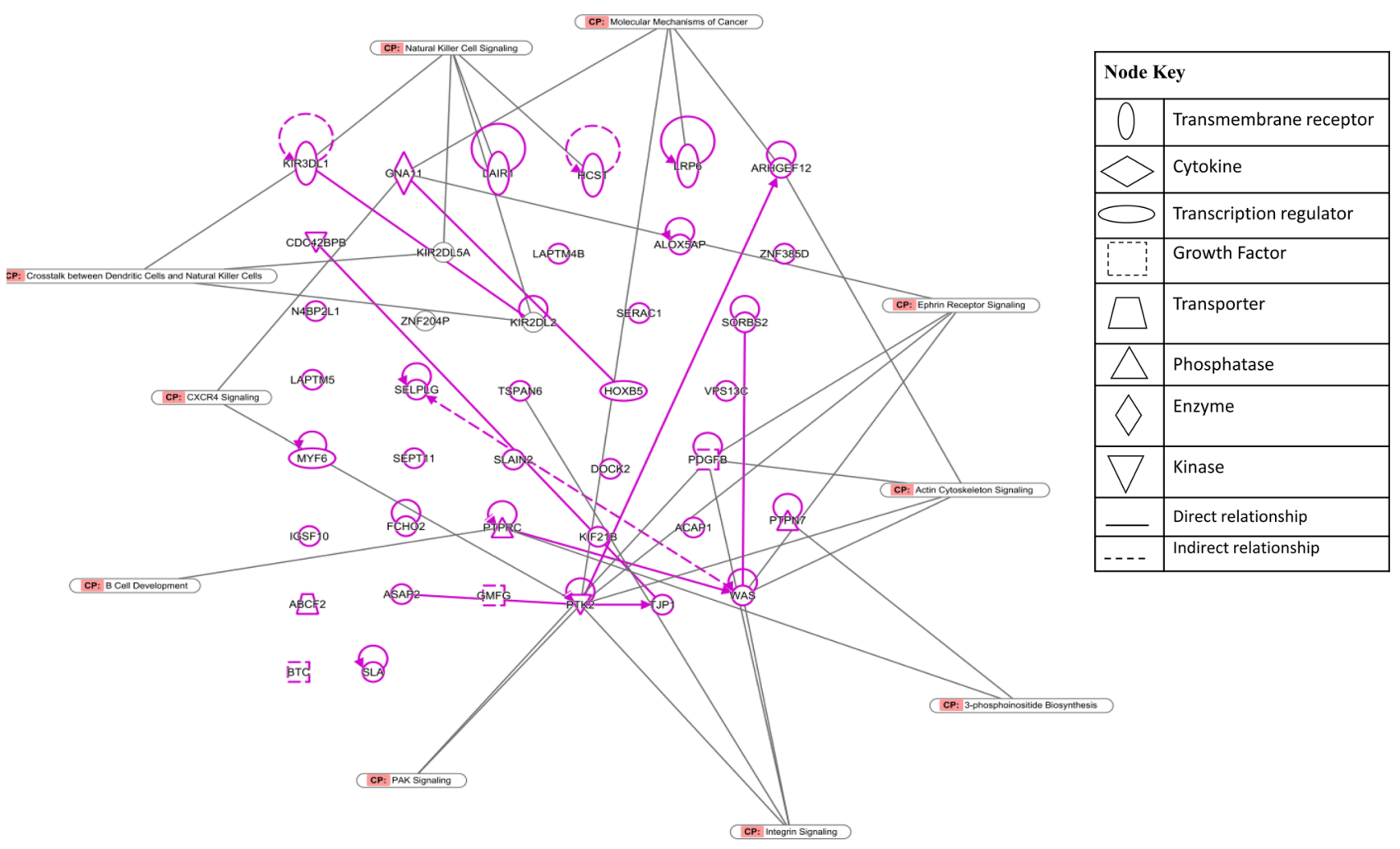

Fig. 6 Biological functions affected by triptolide as determined by mRNA microarray hybridization and Ingenuity Pathway Analysis

protein and promoted apoptotic cell death of drugsensitive parental KB cells and multidrug-resistant KB-7D and KB-tax cells [46]. Besides, triptolide changed the activity of P-glycoprotein drug efflux and mRNA expression of MDR genes [9]. We have comparable results that triptolide strongly inhibited the growth not only of drug-sensitive CCRF-CEM cells but also MDR P-glycoprotein overexpressing CEM/ADR5000 cells in the nanomolar range.
Collateral sensitivity (hypersensitivity) is occasionally observed in ABC-transporter-expressing cells. This event has been well known for several years in ABCB1 (P-gp/MDR1) and MRP1 overexpressing tumor cells [47, 48]. Interestingly, P-glycoprotein overexpressing CEM/ ADR5000 cells revealed collateral sensitivity to triptolide in comparison with their parental drug-sensitive counterparts. Collateral sensitivity represents an interesting phenomenon
Fig. 7 Effect of triptolide on NF- $\kappa$ B activity

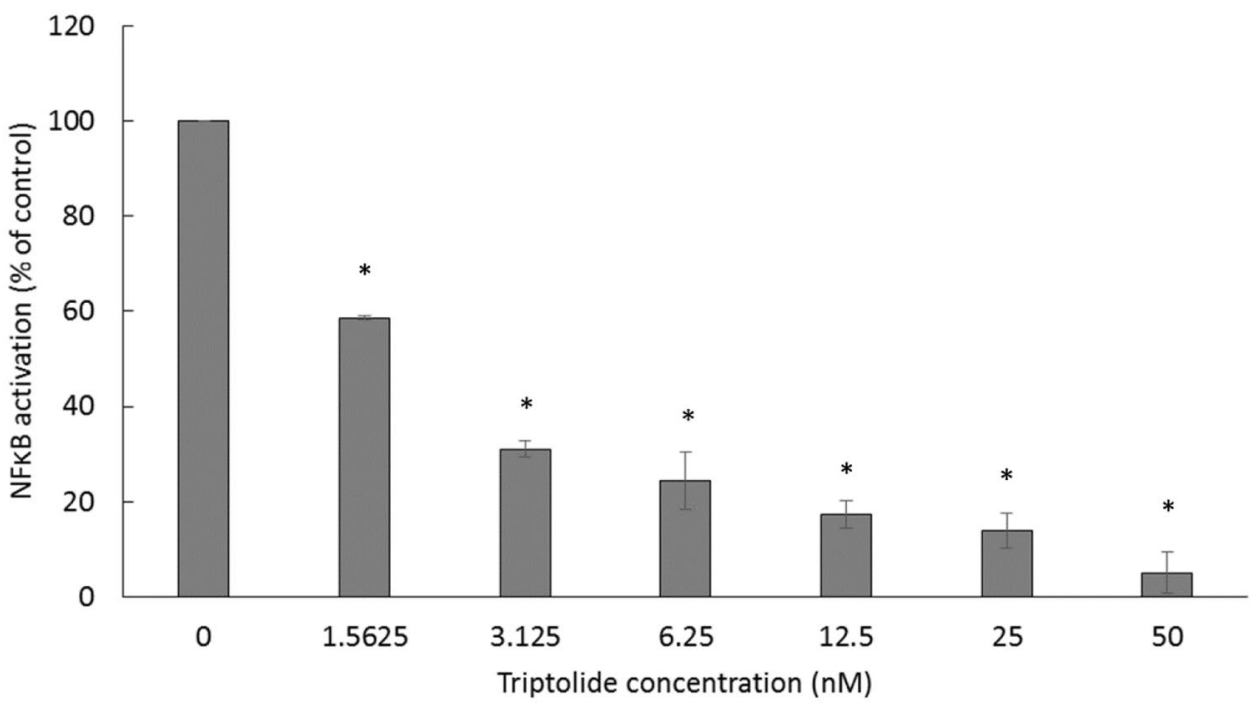



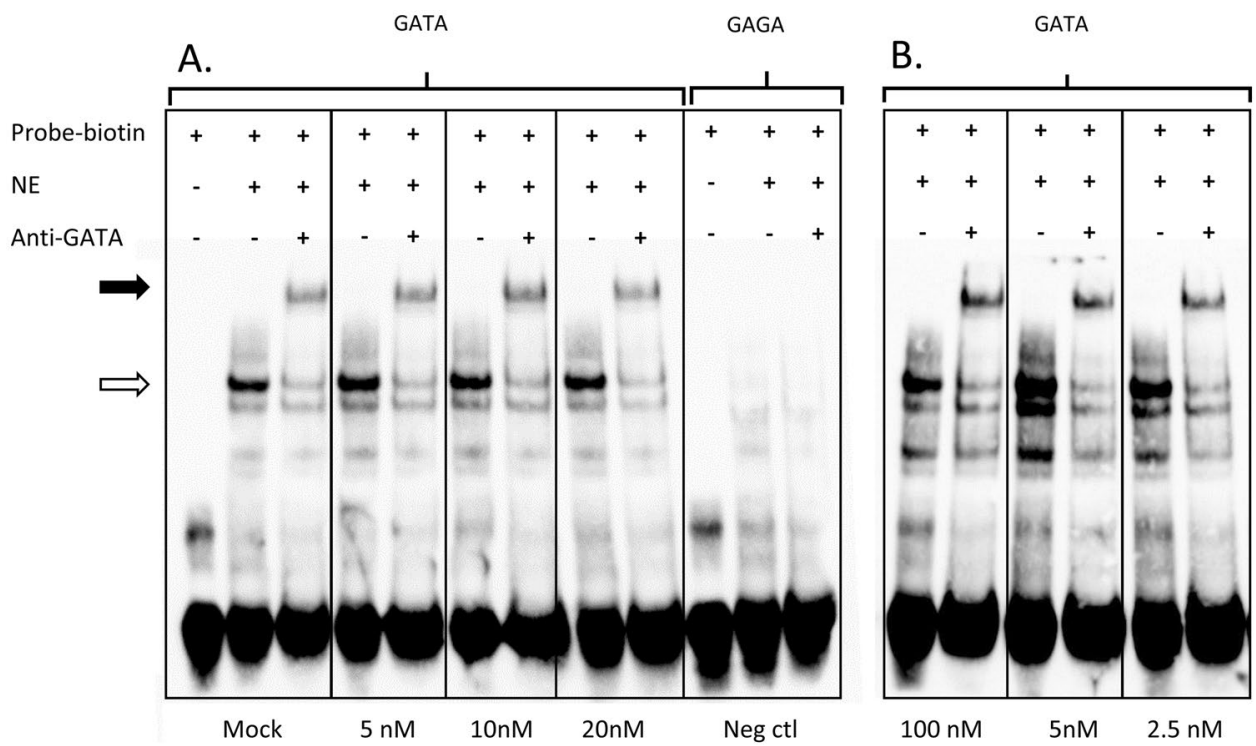

Fig. 8 EMSA Testing was performed with 48-bp biotinylated probes spanning the GATA1 site investigated. A The wild-type probe (GATA) exhibited a shift (white arrow) upon incubation with nuclear extract (NE) from K562 cells, mock-treated or pre-incubated with different concentrations of triptolide $(5,10$, and $20 \mathrm{nM})$, and a further supershift (black arrow) with addition of anti-GATA1, detecting binding of GATA1 to the wild-type probe. As a negative control the probe with

from the therapeutic point of view, because it opens the perspective that drug-resistant refractory tumors could be successfully treated with this kind of drugs [49].

EGFR is a member of the ErbB family of receptors. Upon binding with its ligands, such as EGF or TGF- $\alpha$, EGFR homo- or hetero-dimerizes with other ErbB family members to activate downstream signaling cascades after tyrosine phosphorylation. This signaling controls several cellular processes, such as proliferation, survival, and apoptosis. EGFR mutations leading to EGFR overexpression result in cancer development, and EGFR mutations affect the poor prognosis of patients and mediate drug resistance of tumors [50]. The in-frame deletion of the extracellular EGFR domain causes ligand-independent receptor activation and represents a common mutant type in brain tumors, termed $\triangle$ EGFR [51]. Triptolide showed strong inhibitory effects towards both wtEGFR (sensitive) and $\triangle$ EGFR (resistant) with the same concentrations. These results demonstrate that $\Delta$ EGFR does not confer resistance against triptolide, indicating that triptolide might be a suitable candidate to treat drug-resistant tumors with $\triangle \mathrm{EGFR}$ mutation.

The relationship between the gene expression patterns and the drug responses was investigated using the tumor cell line panel of the NCI developmental therapeutic program. We identified a gene expression profile, which was significantly related to the $\log _{10} \mathrm{IC}_{50}$ values of the cell lines to triptolide. COMPARE analysis identified a set of genes from several functional groups (e.g., cell morphology, a disrupted GATA1 site (GAGA) showed no shift with nuclear extract and hence no supershift could be detected. B Further testing was performed (controls not shown) with higher and lower concentrations of triptolide (100 and $2.5 \mathrm{nM}$ ) when the incubation time was prolonged from $5 \mathrm{~min}$ to 10 . For all concentrations tested there are clear shifts and supershifts further indicating that triptolide does not inhibit GATA1 protein binding to the probes

transmembrane, ribosomal proteins, protein tyrosine phosphatase, and microtubule formation).

Cluster analyses were carried out to predict, whether the cancer cell lines were sensitive or resistant to a cytotoxic drug [52]. The distribution of triptolide-sensitive or -resistant cell lines differed significantly among the different clusters. The portion of sensitive cells in clusters 1 and 5 was much higher than in clusters 2, 3, 4 and 6. Cluster 1 included $75 \%$ sensitive cells and $25 \%$ resistant cells. Cluster 2 contained $30 \%$ sensitive cell lines and $70 \%$ resistant cell lines. Cluster 3 contained $38 \%$ sensitive cell lines and $62 \%$ resistant cell lines. Cluster 4 had $20 \%$ sensitive cells and $80 \%$ resistant cells. Cluster 5 contained $81 \%$ sensitive cell lines and 19\% resistant cell lines. Cluster 6 included $100 \%$ resistant cell lines. This distribution showed significant differences among the clusters as demonstrated by the chi square test $\left(p=0.65 \times 10^{-2}\right)$. The cluster analysis identified two clusters with predominantly triptolide-sensitive and four clusters with predominantly triptolide-resistant cell lines. What does this mean for cancer therapy? By applying this two-step approach with COMPARE and cluster analyses, it was possible to predict cellular drug response by gene expression profiling of cell lines. It is not beyond the scope of imagination that similar approaches may be applied to predict the sensitivity of individual tumors of patients towards standard chemotherapeutic drugs and also cytotoxic compounds such as triptolide. In case resistance to standard chemotherapy occurs, the 
oncologist could switch to cytotoxic natural products which are still active in these otherwise resistant tumors. Hence, the estimation of sensitivity or resistance to cytotoxic drugs by mRNA expression profiles may be applied for novel strategies of individualized cancer treatment and precision medicine, because an approach like this could provide opportunity to determine prior to therapy, whether or not an individual tumor would react to specific drugs or natural products.

In addition to the prediction of sensitivity or resistance to specific anticancer compounds, gene expression profiling coupled with COMPARE and cluster analyses can be used to identify relevant molecular mechanisms of triptolide (and other anticancer drugs and natural products) to unravel underlying molecular modes of action of drugs. In the case of triptolide, we found that NF- $\mathrm{\kappa B}$ plays an important role for the anticancer activity of triptolide. NF- $\mathrm{\kappa B}$ is a ubiquitous transcription factor that controls the expression of genes involved in inflammation, the immune response, cell proliferation, and apoptosis [53]. Interestingly, the NF- $\mathrm{kB}$ binding motif was identified in the upstream promoter regions of all genes, which were identified by COMPARE analysis, demonstrating that NF- $\mathrm{KB}$ is a crucial transcription regulator of triptolide's activity in cancer cells.

NF-KB is cell nuclear factor, which is related to transcription regulation in the process of inflammation, stress, cell growth and proliferation. NF-кB promotes cell proliferation, cell apoptosis and plays a crucial role for the tumor development. NF- $\mathrm{KB}$ is a heterologous dimer composed of $\mathrm{p} 50$ and $\mathrm{p} 65$. Triptolide inhibits the transactivation effect of the p65 subunit of NF-кB and promotes cell apoptosis [10]. Triptolide also indirectly inhibits NF-кB signaling through the AKT/GSK3 $3 / \mathrm{mTOR}$ pathway and induces apoptosis in ovarian cancer by inhibition of NF- $\mathrm{KB}$ expression $[54,55]$.

IPA was carried out to predict molecular mechanism of triptolide using COMPARE and hierarchical cluster analyses genes. IPA indeed showed cellular processes revealing the anti-tumor activity of triptolide. Furthermore, it presented the ZFPM1 (friend of GATA1) as a top candidate in the upstream regulators list. These results are in accordance with the data obtained from the motif analyses. Therefore, we wanted to investigate the inhibition of GATA1 function by triptolide. To the best of our knowledge, the effect of triptolide towards GATA1 is described here for the first time. EMSA experiments displayed that triptolide has no apparent effect on GATA1 binding to its motif. One study showed that GATA1 was up-regulated in Sertoli cells upon treatment with triptolide for 15 days. Then, the authors concluded that triptolide has no effect at the level of Gatal and the change in the expression was probably due to cellular changes leading to spermatids formation [56].

In conclusion, triptolide showed remarkable cytotoxic effect in different sensitive and drug-resistant cancer cell lines. In particular, P-glycoprotein overexpressing CEM/ ADR5000 cells were collateral sensitive toward triptolide. Other investigations were performed to understand the mechanism of action of triptolide. Bioinformatics tools predicted the sensitivity or resistance of tumor cells to triptolide using $60 \mathrm{NCI}$ cell lines. Ingenuity Pathway Analysis identified cellular processes and signaling pathways of genes involved in the mechanisms of action of PT. Finally, triptolide strongly inhibited the activity of NF- $\mathrm{KB}$, while it did not show significant effect towards GATA1.

Acknowledgements We are thankful to the Ministry of Higher Education and Scientific Research and to the Al-Neelain University, Khartoum, Sudan and Johannes Gutenberg University for supporting MD.

Authors' contributions E.-J. Seo and M. Dawood performed experiments and wrote the paper. A. Hult performed the experiments and reviewed the paper. M. Olsson supervised the experiments and reviewed the paper. T. Efferth designed, supervised this study and wrote the paper.

Funding Open Access funding enabled and organized by Projekt DEAL.

Availability of data and materials All data generated or analysed during this study are included in this published article.

\section{Declarations}

Ethics approval and consent to participate This study is not involved in human participants and animals.

Consent for publication We give our consent for the publication of identifiable details, which can include photograph(s) and/or videos and/or case history and/or details within the text ("Material") to be published in Investigational new drugs.

Disclosure of potential conflicts of interest The authors declare that there is no conflict of interest.

Research involving human participants and/or animals This study does not include human participants and animals.

Informed consent All data generated or analysed during this study are included in this published article.

Open Access This article is licensed under a Creative Commons Attribution 4.0 International License, which permits use, sharing, adaptation, distribution and reproduction in any medium or format, as long as you give appropriate credit to the original author(s) and the source, provide a link to the Creative Commons licence, and indicate if changes were made. The images or other third party material in this article are included in the article's Creative Commons licence, unless indicated otherwise in a credit line to the material. If material is not included in the article's Creative Commons licence and your intended use is not permitted by statutory regulation or exceeds the permitted use, you will need to obtain permission directly from the copyright holder. To view a copy of this licence, visit http://creativecommons.org/licenses/by/4.0/. 


\section{References}

1. Kupchan SM et al (1972) Triptolide and tripdiolide, novel antileukemic diterpenoid triepoxides from Tripterygium wilfordii. $\mathrm{J}$ Am Chem Soc 94(20):7194-7195

2. Chugh R et al (2012) A Preclinical Evaluation of Minnelide as a Therapeutic Agent Against Pancreatic Cancer. Science Translational Medicine 4(156)

3. Guo X et al (2016) Protective effects of triptolide on TLR4 mediated autoimmune and inflammatory response induced myocardial fibrosis in diabetic cardiomyopathy. J Ethnopharmacol 193:333-344

4. Long C et al (2016) Triptolide decreases expression of latencyassociated nuclear antigen 1 and reduces viral titers in Kaposi's sarcoma-associated and herpesvirus-related primary effusion lymphoma cells. Int J Oncol 48(4):1519-1530

5. Liu Z et al (2015) Computational prediction and experimental validation of a novel synthesized pan-PIM inhibitor PI003 and its apoptosis-inducing mechanisms in cervical cancer. Oncotarget 6(10):8019-8035

6. Zhao Q et al (2015) Natural products triptolide, celastrol, and withaferin A inhibit the chaperone activity of peroxiredoxin I. Chem Sci 6(7):4124-4130

7. Titov DV et al (2011) XPB, a subunit of TFIIH, is a target of the natural product triptolide. Nat Chem Biol 7(3):182-188

8. Han R et al (2012) Triptolide in the treatment of psoriasis and other immune-mediated inflammatory diseases. Br J Clin Pharmacol 74(3):424-436

9. Yi JM et al (2016) Triptolide Induces Cell Killing in MultidrugResistant Tumor Cells via CDK7/RPB1 Rather than XPB or p44. Mol Cancer Ther 15(7):1495-1503

10. Park SW, Kim YI (2013) Triptolide induces apoptosis of PMA-treated THP-1 cells through activation of caspases, inhibition of NF-kappa B and activation of MAPKs. Int J Oncol 43(4):1169-1175

11. Yang SM et al (2003) Triptolide inhibits the growth and metastasis of solid tumors. Mol Cancer Ther 2(1):65-72

12. Meng CC et al (2014) Targets and molecular mechanisms of triptolide in cancer therapy. Chin J Cancer Res 26(5):622-626

13. Darnell JE (2002) Transcription factors as targets for cancer therapy. Nat Rev Cancer 2(10):740-749

14. Zheng R, Blobel GA (2010) GATA Transcription Factors and Cancer. Genes Cancer 1(12):1178-1188

15. Lin A, Karin M (2003) NF-kappaB in cancer: a marked target. Semin Cancer Biol 13(2):107-114

16. Baud V, Karin M (2009) OPINION Is NF-kappa B a good target for cancer therapy? Hopes and pitfalls. Nat Rev Drug Discovery $8(1): 33-40$

17. Ohneda $\mathrm{K}$ et al (2002) A minigene containing four discrete cis elements recapitulates GATA-1 gene expression in vivo. Genes Cells 7(12):1243-1254

18. Bresnick EH et al (2005) Developmental control via GATA factor interplay at chromatin domains. J Cell Physiol 205(1):1-9

19. Shimizu R, Engel JD, Yamamoto M (2008) GATA1 - related leukaemias. Nat Rev Cancer 8(4):279-287

20. Tsang SY et al (2015) Glioma Association and Balancing Selection of ZFPM2. Plos One. 10(7).

21. Cai Q et al (2016) CBFbeta-SMMHC creates aberrant megakaryocyte-erythroid progenitors prone to leukemia initiation in mice. Blood 128(11):1503-1515

22. Efferth $\mathrm{T}$ et al (2003) Molecular modes of action of artesunate in tumor cell lines. Mol Pharmacol 64(2):382-394

23. Saeed $M$ et al (2015) Activity of the dietary flavonoid, apigenin, against multidrug-resistant tumor cells as determined by pharmacogenomics and molecular docking. J Nutr Biochem 26(1):44-56

24. Alley MC et al (1988) Feasibility of Drug Screening with Panels of Human-Tumor Cell-Lines Using a Microculture Tetrazolium Assay. Can Res 48(3):589-601

25. O'Brien J et al (2000) Investigation of the Alamar Blue (resazurin) fluorescent dye for the assessment of mammalian cell cytotoxicity. Eur J Biochem 267(17):5421-5426

26. Kuete $\mathrm{V}$ et al (2016) Cytotoxicity of methanol extracts of Annona muricata, Passiflora edulis and nine other Cameroonian medicinal plants towards multi-factorial drug-resistant cancer cell lines. Springerplus 5

27. Kuete V et al (2016) Cytotoxicity of methanol extracts of 10 Cameroonian medicinal plants towards multi-factorial drug-resistant cancer cell lines. Bmc Complementary and Alternative Medicine 16

28. Scherf U et al (2000) A gene expression database for the molecular pharmacology of cancer. Nat Genet 24(3):236-244

29. Amundson SA et al (2008) Integrating global gene expression and radiation survival parameters across the 60 cell lines of the National Cancer Institute Anticancer Drug Screen. Can Res $68(2): 415-424$

30. Wosikowski K et al (1997) Identification of epidermal growth factor receptor and c-erbB2 pathway inhibitors by correlation with gene expression patterns. Jnci-Journal of the National Cancer Institute 89(20):1505-1515

31. Evans A et al (2008) Glut-1 as a therapeutic target: increased chemoresistance and HIF-1-independent link with cell turnover is revealed through COMPARE analysis and metabolomic studies. Cancer Chemother Pharmacol 61(3):377-393

32. Fagan V et al (2010) One-pot double intramolecular homolytic aromatic substitution routes to dialicyclic ring fused imidazobenzimidazolequinones and preliminary analysis of anticancer activity. Org Biomol Chem 8(14):3149-3156

33. Efferth $\mathrm{T}$ et al (2011) Cytotoxic activity of secondary metabolites derived from Artemisia annua L. towards cancer cells in comparison to its designated active constituent artemisinin. Phytomedicine 18(11):959-969

34. Weinstein JN et al (1997) An information-intensive approach to the molecular pharmacology of cancer. Science 275(5298):343-349

35. Liu T et al (2011) Cistrome: an integrative platform for transcriptional regulation studies. Genome Biology 12(8)

36. Zeino $\mathrm{M}$ et al (2014) The ability of molecular docking to unravel the controversy and challenges related to P-glycoprotein-a wellknown, yet poorly understood drug transporter. Invest New Drugs 32(4):618-625

37. Dawood M, Hamdoun S, Efferth T (2018) Multifactorial Modes of Action of Arsenic Trioxide in Cancer Cells as Analyzed by Classical and Network Pharmacology. Front Pharmacol 9:143

38. Ye J et al (2019) Transcriptome analysis identifies key regulators and networks in Acute myeloid leukemia. Hematology 24(1):487-491

39. Kadioglu O, Efferth T (2015) Pharmacogenomic Characterization of Cytotoxic Compounds from Salvia officinalis in Cancer Cells. J Nat Prod 78(4):762-775

40. Kadioglu O et al (2016) Evaluating ancient Egyptian prescriptions today: Anti-inflammatory activity of Ziziphus spinachristi. Phytomedicine 23(3):293-306

41. Dawood M, Ooko E, Efferth T (2019) Collateral Sensitivity of Parthenolide via NF-kappaB and HIF-alpha Inhibition and Epigenetic Changes in Drug-Resistant Cancer Cell Lines. Front Pharmacol 10:542

42. Moller $\mathrm{M}$ et al (2018) Disruption of a GATA1-binding motif upstream of XG/PBDX abolishes $\mathrm{Xg}(\mathrm{a})$ expression and resolves the Xg blood group system. Blood 132(3):334-338 
43. Andrews NC, Faller DV (1991) A rapid micropreparation technique for extraction of DNA-binding proteins from limiting numbers of mammalian cells. Nucleic Acids Res 19(9):2499

44. Kiviharju TM et al (2002) Antiproliferative and proapoptotic activities of triptolide (PG490), a natural product entering clinical trials, on primary cultures of human prostatic epithelial cells. Clin Cancer Res 8(8):2666-2674

45. Joshi P, Vishwakarma RA, Bharate SB (2017) Natural alkaloids as P-gp inhibitors for multidrug resistance reversal in cancer. Eur J Med Chem 138:273-292

46. Chen $\mathrm{M}$ et al (2015) Triptolide inhibits TGF-beta1-induced cell proliferation in rat airway smooth muscle cells by suppressing Smad signaling. Exp Cell Res 331(2):362-368

47. Hutchison DJ (1963) Cross Resistance and Collateral Sensitivity Studies in Cancer Chemotherapy. Adv Cancer Res 7:235-350

48. Gottesman MM, Pastan I (1993) Biochemistry of MultidrugResistance Mediated by the Multidrug Transporter. Annu Rev Biochem 62:385-427

49. Hall MD, Handley MD, Gottesman MM (2009) Is resistance useless? Multidrug resistance and collateral sensitivity. Trends Pharmacol Sci 30(10):546-556

50. Zhang HT et al (2007) ErbB receptors: from oncogenes to targeted cancer therapies. J Clin Investig 117(8):2051-2058
51. Shinojima N et al (2003) Prognostic value of epidermal growth factor receptor in patients with glioblastoma multiforme. Can Res 63(20):6962-6970

52. Sertel S et al (2012) Factors Determining Sensitivity and Resistance of Tumor Cells to Arsenic Trioxide. Plos One 7(5)

53. Li Q, Verma IM (2002) NF-kappaB regulation in the immune system. Nat Rev Immunol 2(10):725-734

54. Li M et al (2014) NF-kappaB signaling inhibition and anticancer activities of LLDT-246 on human colorectal cancer HCT-116 cells in vitro. Biomed Pharmacother 68(5):527-535

55. Ou CC et al (2012) Triptolide Transcriptionally Represses HER2 in Ovarian Cancer Cells by Targeting NF-kappaB. Evid Based Complement Alternat Med p. 350239

56. Li CZ et al (2015) The role of breast cancer resistance protein (Bcrp/Abcg2) in triptolide-induced testis toxicity. Toxicology Research 4(5):1260-1268

Publisher's Note Springer Nature remains neutral with regard to jurisdictional claims in published maps and institutional affiliations. 